\title{
Method of Pulmonary Arterial Pressure Correction During Pulmonectomy by Forming Intervascular Anastomoses (Experimental Study)
}

DOI: $10.17691 / \mathrm{stm} 2019.11 .3 .05$

Received September 12, 2018

M.T. Nadyrov, Doctoral Student, Assistant, Department of Surgery No.11;

Y.A. Almabayev, MD, DSc, Professor, Head of the Department of Clinical Anatomy and Operative Surgery';

A.N. Baimahanov, MD, PhD, Associate Professor, Head of the Department of Surgery No.1';

I.R. Fakhradiyev, Doctoral Student, Head of the Experimental Medicine Laboratory';

A.Y. Almabayeva, MD, DSc, Professor, Department of Anatomy²;

B.D. Tanabayev, MD, DSc, Professor, Head of the Department of Morphological Disciplines ${ }^{3}$;

M.B. Kulimbet, Master of Sciences in Epidemiology, Research Associate';

A.D. Raimhanov, Doctor PhD, Assistant, Department of Surgery No.1

${ }^{1}$ Kazakh National Medical University, 94 Tole-bi, Almaty, 050000, Republic of Kazakhstan;

${ }^{2}$ Astana Medical University, 49a Beibitshilik St., Nur-Sultan, 010000, Republic of Kazakhstan;

${ }^{3}$ South-Kazakhstan State Pharmaceutical Academy, 1/1 Al-Farabi Square, Shymkent, 160019, Republic of Kazakhstan

The aim of the study was to assess the possibility of reducing pulmonary arterial pressure by creating various types of intervascular anastomoses during left-sided pulmonectomy in the experiment.

Materials and Methods. The experimental study was carried out on 102 laboratory animals (mini pigs) aged 24-27 months weighing 12-17 kg. Three series of experiments have been performed. In the first series $(n=34)$, left-sided pulmonectomies which corresponded to the removal of 42 weight percent of pulmonary tissue were done. In the second series $(n=34)$, arteriovenous shunting of the pulmonary circulation by end-to-end connection of the proximal sections of the inferior lobar artery and the like-named vein on the operated side was carried out during left-sided pulmonectomies. In the third series $(n=34)$, arterio-arterial shunting by connecting the proximal section of the superior lobar artery on the operated side with the distal section of the subclavian artery on the same side was performed during left-sided pulmonectomies.

Results. Lethality of the animals after pulmonectomy performed by a conventional method without anastomoses (series 1 ) was $1: 3$ (10 of 34 operated pigs died), and 8 of 10 died of acute edema.

Among the animals undergone pulmonectomy with arteriovenous shunt functioning between the pulmonary artery and the vein on the operated side (series 2), lethality appeared to be smaller, about 1:6 (6 of 34 mini pigs died). None of the animals suffered death from acute pulmonary edema.

Lethality among the animals of series 3 , in which the pulmonary artery on the side of the removed lung was connected with the distal section of the subclavian artery, was the highest making half of the total number of the operated animals. 14 mini pigs died from acute pulmonary edema within the first hours after the operation, 4 died 4 months later from right ventricular failure.

Conclusion. Pulmonectomy with the shunt functioning between the inferior lobar artery and vein on the operated side provides the possibility to avoid acute edema of the remaining lung during the operation and soon after it.

Key words: pulmonectomy; pulmonary insufficiency; pulmonary arterial hypertension; intervascular anastomoses.

\section{Introduction}

According to the available data, the rate of postoperative recurrences associated with pulmonectomy is from 5 to $30 \%$ [1]. Ablation of the lung or a large volume of pulmonary tissue is known to result in the increase of total vascular network resistance and almost 2-fold growth of arterial pressure in the remaining part of pulmonary circulation [2]. Of great importance in the mechanism of developing pulmonary insufficiency are diverse disorders of metabolism and the system of peripheral blood circulation leading ultimately to hemostasis impairment and later to irreversible functional and morphological alterations of the body system $[3,4]$.

It should be noted that hemodynamic disturbance in the remaining lung occurs already at the moment of pulmonary artery ligation. Impairment of the portal venous bloodstream occurs during bronchus suturing while that of the local bloodstream already

Corresponding author: Ildar R. Fakhradiyev, e-mail: ildariko@mail.ru 
$3 \mathrm{~h}$ after pulmonectomy, and even 3 months later its compensation does not take place [5].

Blood oxygenation disorder during pulmonectomy is believed to be one of the main causes of postoperative hypoxia development and fatal outcomes associated with it. Therefore, ventilation-perfusion disorders after pulmoectomy are considered the primary etiological factor of respiratory dysfunction due to twofold increase of blood flow via a single lung. Gas exchange processes in the lungs are closely interconnected with other functions primarily with metabolic and detoxicating activity of the lung parenchyma [6].

The current methods of postoperative disorder correction after pulmonectomy include infusiontransfusion maintenance of hemodynamics, antibacterial chemoprophylaxis, and perioperative support.

It is also proposed to administer more actively preparations with antihypoxic properties which will correct metabolic disturbances in a single lung and decrease the intensity of systemic effects of hypoxia [7].

Inadequate increase of pulmonary arterial pressure can result in heavy edema of the remaining lung and acute right ventricular insufficiency during the operation or within several hours after it. In remote periods after pulmonectomy, full restoration of the impaired cardiopulmonary system does not occur even when these complications have been successfully avoided and progressive pulmonary arterial hypertension leads to the development of cor pulmonale [8].

Since pulmonary arterial hypertension plays a pathogenetic role in the development of acute pulmonary edema and right ventricular insufficiency, it may be supposed that the reduction of the pressure in the pulmonary artery by creating intervascular anastomoses of various types must help to prevent edema of the second lung during the operation and later to prevent and delay the development of right ventricular insufficiency. To verify this supposition, three series of experiments have been conducted by us.

The aim of the study was to assess the possibility of reducing pulmonary arterial pressure by creating various types of intervascular anastomoses during left-sided pulmonectomy in the experiment.

\section{Materials and Methods}

The study was carried out on 102 laboratory animals (mini pigs) aged 24-27 months weighing 12-17 kg housed in the vivarium of $B$. Atchabarov Research Institute of Fundamental and Applied Medicine (Republic of Kazakhstan) with a standard ration and care.

The fact that mini pigs are a selection group bred as a biological resource of laboratory animals and are available for medico-biological experiments explains the reason for our choice [9].

The animals were kept and the experiments conducted in compliance with the Guide for the Care and Use of Laboratory Animals (National Research
Council, 2011) and the ethical principles of the European Convention for the Protection of Vertebrate Animals used for Experimental and Other Scientific Purposes (Strasbourg, 2006).

A sample volume of the laboratory animals was determined using $G^{*}$ Power v. 3.0.10 program. A large effect size of 0.40 , three groups of comparison, and effect power of 0.95 with 0.05 level of significance have been selected. Thus, the sample volume in our study amounted to 102 laboratory animals $(n=34$ in each group).

Each group of animals participated randomizingly in a separate series of experiments.

In series 1, left-sided pulmonectomies were performed which corresponded to the removal of 42 weight percent of the lung tissue. Animals were followed-up for a year after the operation.

In series 2, left-sided pumonectomies and arteriovenous shunting of the pulmonary circulation by end-to-end anastomosis between the proximal sections of the lobar artery and vein on the operated side were conducted. A follow-up period after the operation lasted 1 year.

In series 3, left-sided pulmonectomies and arterioarterial shunting by connecting the end of the proximal section of the lobar artery on the operated side with the distal section of the subclavian artery on the same side were performed. A follow-up period after the operation lasted 3 months.

Operations on the laboratory animals were done in the operation unit of the Experimental Medicine Laboratory at the B. Atchabarov Research Institute of Fundamental and Applied Medicine.

Animals with a carefully shaven operative field and under general anesthesia (10 mg/kg Kalipsol; $1.0 \mathrm{mg} / \mathrm{kg}$ Lysthenon; 1\% 1.5-2.5 mg/kg Propofol; the dose and time of substance introduction were registered in the experiment log book) were fixed on a bench lying supine. A peripheral catheter was inserted in the marginal ear vein, sensors for electrocardiography were attached to the chest, pulse oximetry sensor was fixed to the tongue to monitor the saturation of peripheral blood with oxygen.

At the next stage, a myorelaxant (Arduan, $0.05 \mathrm{mg} / \mathrm{kg}$ ) was intravenously injected to the animals and tracheal intubation according to Vachnadze technique [10] was performed using a \#4-5 curved Macintosh-type blade and $6-7 \mathrm{~mm}$ endotracheal tube. Prior to tube insertion during direct laryngoscopy, the glottis was irrigated with lidocaine, the tubes were lubricated with a lubricant. After intubation of the trachea, the adequacy of tube position was auscultatively tested. The action of propofol and analgetics was potentiated with droperidol at a dose of $0.3 \mathrm{mg} / \mathrm{kg}$ every $45 \mathrm{~min}$ using an automatic syringe pump Perfusor Compact (B. Broun, Germany).

The animals were attached to the system of artificial lung ventilation HPV760 (Puritan Bennett, USA), forced lung ventilation was performed with 1:1 oxygen-air gas 
mixture. ECG and heart rate were registered in real time using an Intellivue (Philips) monitoring system.

Lateral thoracotomy in the projection of the fourth intercostal space on the left was performed. A linear incision of the skin was made along the intercostal space between the fourth and fifth ribs, superficial and intercostal muscles were divided by blunt dissection, the pleural cavity was opened, ribs were moved apart with the help of a yard retractor.

Pulmonectomy was performed with separate ligation of the root elements of the lung lobes starting with the lower lobe. Immediately after pulmonectomy, blood pressure in the pulmonary artery was measured.

During arteriovenous pulmonary circulation shunting after anesthesia of the reflexogenic zones with $0.25 \%$ solution of novocaine, the artery and vein of the inferior lobe of the left lung was isolated to the length of about $3 \mathrm{~cm}$, this lobe was removed and the ends of the mobilized artery and vein were connected with an ASC-8 apparatus (Russia). Having verified the shunt patency, pressure in the pulmonary artery was measured.

During arterio-arterial pulmonary circulation shunting after anesthesia of the reflexogenic zones with $0.25 \%$ solution of novocaine, the lobar artery of the lung on the operated side and the subclavian artery on the same side were isolated, the mobilized arteries were also connected with the ASC-8 apparatus.

Pressure in the pulmonary artery was measured using Doppler echocardiography using ultrasound ACUSON CV-70 apparatus (Siemens, Germany) with the help of P4-2 transducer from the apical access in M-, B-mode, pulsed wave, continuous wave, color, and tissue Doppler modes. Systolic and diastolic indices were calculated: maximal velocity of the second positive peak Sm, maximal velocity of the first negative peak Em, maximal velocity of the second negative peak $\mathrm{Am}, \mathrm{Em} / \mathrm{Am}$ ratio $[11,12]$.

The animals were withdrawn from narcosis by discontinuing anesthesiological preparations. When spontaneous respiration stabilized, animals were extubated and placed to the prepared clean enclosure.

Ketonal $(20 \mathrm{mg} / \mathrm{kg})$ was administered postoperatively during the first day to relieve the pain. Further, narcotic agents to kill the pain were not required.

In the course of the experiment, the laboratory animals were kept in the vivarium of the B. Atchabarov Research Institute of Fundamental and Applied Medicine in compliance with the standard of maintenance and care for postoperative animals developed in cooperation with the Experimental Medicine Laboratory of the National Medical University (Republic of Kazakhstan).

The laboratory animals were withdrawn from the experiment according to the method developed by Almabayeva [13].

The histological material was collected during surgical procedures according to the Korzhevsky's method [14].

The animal biological material was utilized in compliance with the rules for utilization and destruction of biological wastes (Rules of utilization, destruction of biological wastes were developed in accordance with subparagraph $46-11$ of clause 8 of the Law "On Veterinary" of the Republic of Kazakhstan of July 10, 2002).

Data were statistically processed using a software package R 3.4.4 for Windows. Arithmetic mean (M) and standard deviation (SD) were calculated for quantitative variables. Data were presented as $M \pm S D$. Qualitative attributes were described as absolute (n) and relative (\%) values. Coefficients of variability were calculated. Differences between the examined indices were considered statistically significant at $p<0.05$. One-way analysis of variance ANOVA was chosen as a statistical test. It can be explained by the fact that samples of groups were independent and to test the theories, the analysis of variance with F-distribution may be used. The data of the study meet all the requirements of the statistical test chosen: the dependent variable is quantitative, whereas the independent variable is qualitative and have three categories; samples are randomly divided into groups; homogeneity of variances - variances are approximately equal across the groups; there are no non-ordinary values in the examined data; comparative data analysis is performed; three groups are used in the study.

Descriptive statistics (\%) was used to describe the lethality of the experimental animals for the operations of different character.

\section{Results}

Pulmonectomy was performed with separate ligation of the root elements of the lung lobes starting with the lower one. In experimental series 1, blood pressure in the pulmonary artery increased significantly immediately after pulmonectomy (Table 1). In series 2, during arteriovenous pulmonary circulation shunting after anesthesia of the reflexogenic zones with $0.25 \%$ solution of novocaine, the artery and vein of the inferior lobe of the left lung were isolated to the length of about $3 \mathrm{~cm}$, this lobe was removed and the ends of the mobilized artery and vein were connected with an ASC-8 apparatus. Having verified the shunt patency, pressure in the pulmonary artery was measured. The measurements have shown that removal of the inferior lobe of the lung ( $26 \%$ of the lung tissue) did not lead to pressure increase in the system of the pulmonary artery. This pressure also did not rise after the removal of the superior and middle lung lobes with the functioning arteriovenous shunt.

Thus, preliminary arteriovenous shunting of the inferior lobar vessels prevented the rise of blood pressure in the remaining lung when the blood flow in the superior and middle lung lobes was preserved and when all lobes of the operated lung were removed. This fact provides evidence that arteriovenous shunting may serve as a means for preventing acute edema of a single lung and, therefore, right ventricular insufficiency during 


\section{BIOTECHNOLOGIES}

Table 1

Dynamics of the mean pulmonary artery pressure at different terms after pulmonectomy depending on the operation character

\begin{tabular}{|c|c|c|c|c|c|c|c|c|c|}
\hline \multirow{3}{*}{ Operation type } & \multicolumn{9}{|c|}{ Blood pressure in the pulmonary artery $\left(\mathrm{mm} \mathrm{H}_{2} \mathrm{O}\right), \mathrm{M} \pm \mathrm{SD}$} \\
\hline & \multirow{2}{*}{$\begin{array}{c}\text { Before } \\
\text { thoracotomy } \\
\text { (initial pressure) }\end{array}$} & \multirow{2}{*}{$\begin{array}{l}\text { With the clamped shunt } \\
\text { (simulation of lung } \\
\text { removal without shunt) }\end{array}$} & \multicolumn{7}{|c|}{ After pulmonectomy } \\
\hline & & & Week 1 & Month 1 & Month 2 & Month 3 & Month 6 & Month 9 & One year \\
\hline $\begin{array}{l}\text { Left-sided pulmonectomy } \\
\text { by conventional method } \\
\text { (experimental series 1) }\end{array}$ & $360 \pm 10$ & - & $504 \pm 16$ & $432 \pm 14$ & $396 \pm 12$ & $451 \pm 15$ & $490 \pm 15$ & $523 \pm 17$ & $576 \pm 18$ \\
\hline $\begin{array}{l}\text { Left-sided pulmonectomy } \\
\text { with arteriovenous shunting } \\
\text { of the pulmonary circulation } \\
\text { (experimental series 2) }\end{array}$ & $355 \pm 10$ & $576 \pm 18$ & $360 \pm 12$ & $368 \pm 11$ & $359 \pm 10$ & $371 \pm 12$ & $375 \pm 13$ & $383 \pm 12$ & $396 \pm 11$ \\
\hline $\begin{array}{l}\text { Left-sided pulmonectomy } \\
\text { with arterio-arterial intersystem } \\
\text { shunting (experimental series } 3 \text { ) }\end{array}$ & $330 \pm 10$ & $535 \pm 17$ & $535 \pm 16$ & $583 \pm 14$ & $573 \pm 12$ & $595 \pm 15$ & $600 \pm 12$ & - & - \\
\hline
\end{tabular}

the operation and in the early postoperative period. This conclusion was confirmed by the analysis of the operated animal lethality in all three experimental series (see Table 1).

In experimental series 3 , in order to determine more precisely the role of the pulmonary arterial pressure rise in complications and unfavorable outcomes of pulmonectomy, pressure in the remained part of pulmonary circulation was increased by creating endto-end anastomosis between the origin of the superior lobar artery and the distal section of the subclavian artery. Anastomosing of the pulmonary artery with the distal rather than proximal section of the subclavian artery was chosen in order not to exceed the values of increased pulmonary arterial pressure usually observed in pulmonary arterial hypertension. The anastomosis between the arteries was performed with the functioning middle and inferior lobes.

Collaterals of the subclavian artery are so developed that blood pressure in the distal part of the ligated and transected subclavian artery was over $700 \mathrm{~mm}$ $\mathrm{H}_{2} \mathrm{O}$, whereas in the pulmonary artery prepared for anastomosing with the subclavian artery it was only $330 \pm 10 \mathrm{~mm} \mathrm{H}_{2} \mathrm{O}$. When Evans blue was injected in the pulmonary artery, the dye did not flow through the tube towards the subclavian artery but when introduced into the subclavian artery, blood stained with the dye flew through the tube towards the pulmonary artery.

Blood pressure in the pulmonary artery after pulmonectomy with arterio-arterial anastomosis grew by $76.6 \%$ of the initial level during the first week and later by the third month it increased by $81.8 \%$ of the norm. Continuous blood flow from the subclavian to the pulmonary artery created inadequate load on the single lung and right ventricle of the heart.

The analysis of hemodynamics in the pulmonary circulation after pulmonectomy performed by the three described methods showed that favorable conditions created by arteriovenous shunting remain even in the remote periods after the operation (see Table 1).

Only by the end of the year after the operation, increase of the pressure in the pulmonary artery by $10 \%$ of the initial values (up to $395 \pm 10 \mathrm{~mm} \mathrm{H}_{2} \mathrm{O}$ ) has been noted. However, this increase was 6 times less in comparison with the increment of the mean pressure in the pulmonary artery of the animals undergone pulmonectomy without shunting.

In one mini pig after removal of the left lung with arteriovenous anastomosis, pressure in the pulmonary artery increased sharply and reached $580 \mathrm{~mm} \mathrm{H}_{2} \mathrm{O}$ by the sixth month, whereas in other mini pigs of these series it was within the limits of the initial level (374 \pm $12 \mathrm{~mm} \mathrm{H}_{2} \mathrm{O}$ ).

High pressure in the pulmonary artery was caused by thrombosis of the arteriovenous anastomosis as established during rethoracotomy.

In pulmonectomy without shunts, mean pulmonary artery pressure immediately after the operation increases by $40 \%$ of the initial level, then gradually decreases reaching the minimum during the second month.

It may be connected with triggering of the compensatory mechanisms of the remaining lung and enhancement of the function of the intrapulmonary arteriovenous anastomoses. But the mean pressure in the pulmonary artery did not reach the initial level remaining increased by $10 \%$ relative to the norm. Beginning with the third month, it progressively grew and had increased by $60 \%$ of the initial level by the end of the year after the operation.

This is likely to occur due to weakening of compensatory reserves of the operated lung as the result of the sclerotic processes in the tissues with the depletion of the capillary network developed by this time, progressive collagenization of the vessels, bronchi, and alveolar septa. 
Table 2

Lethality of the experimental animals depending on the character of pulmonectomy performed (abs. number/\%)

\begin{tabular}{|c|c|c|c|c|c|c|c|c|}
\hline \multirow{3}{*}{ Operation type } & \multirow{3}{*}{$\begin{array}{l}\text { Operated } \\
\text { animals }\end{array}$} & \multicolumn{7}{|c|}{ Cause of death and the number of the died animals } \\
\hline & & \multirow{2}{*}{$\begin{array}{c}\text { Narcosis } \\
\text { error }\end{array}$} & \multicolumn{3}{|c|}{ Lung edema } & \multirow{2}{*}{$\begin{array}{l}\text { Thrombosis } \\
\text { of the pulmonary artery } \\
\text { during catheterization }\end{array}$} & \multirow{2}{*}{$\begin{array}{c}\text { Pleural } \\
\text { empyema }\end{array}$} & \multirow{2}{*}{$\begin{array}{l}\text { Right } \\
\text { ventricular } \\
\text { failure }\end{array}$} \\
\hline & & & $\begin{array}{l}\text { In the first } \\
\text { hours }\end{array}$ & On day 1 & On day 2 & & & \\
\hline $\begin{array}{l}\text { Left-sided pulmonectomy } \\
\text { by conventional method } \\
\text { (experimental series } 1 \text { ) }\end{array}$ & $34 / 100$ & $2 / 5.9$ & $4 / 11.8$ & $2 / 5.9$ & $2 / 5.9$ & - & - & - \\
\hline $\begin{array}{l}\text { Left-sided pulmonectomy } \\
\text { with arteriovenous shunting } \\
\text { of the pulmonary circulation } \\
\text { (experimental series 2) }\end{array}$ & $34 / 100$ & $2 / 5.9$ & - & - & - & $2 / 5.9$ & $2 / 5.9$ & - \\
\hline $\begin{array}{l}\text { Left-sided pulmonectomy } \\
\text { with arterio-arterial intersystem } \\
\text { shunting (experimental series } 3 \text { ) }\end{array}$ & $34 / 100$ & - & $14 / 41.2$ & - & - & - & - & $4 / 11.8$ \\
\hline
\end{tabular}

The obtained data on the influence of various types of anastomoses in pulmonectomy on the rate of postoperative recurrences are also confirmed by the results of lethality analysis among the operated animals (Table 2).

Animal lethality after pulmonectomies performed by the conventional method without shunts (series 1) was $1: 3$ (10 of 34 operated animals died), 8 of 10 having died of acute edema of the remained lung, and only 2 mini pigs died of anesthesia errors.

Among the animals undergone pulmonectomy with arteriovenous shunt functioning between the pulmonary artery and vein of the operated side (series 2), lethality appeared to be significantly smaller than in the animals of series 1 being about 1:6 (6 of 34 mini pigs died). None of the animals suffered death from acute pulmonary edema: 2 died due to narcosis error, 2 of thrombosis of the pulmonary artery during cardiac catheterization, and 2 of pleura empyema on day 7 after the operation.

Lethality among the animals of series 3 , in which the pulmonary artery on the side of the removed lung was connected with the distal section of the subclavian artery, was the highest making half of the total number of the operated animals. 14 mini pigs died of acute pulmonary edema within the first hours after the operation, 4 died 4 months later of the right ventricular failure.

Thus, of the examined methods, the operation for lung excision with a functioning anastomosis between the pulmonary vein and pulmonary artery on the operated side provides the greatest possibilities to avoid acute edema of the remained lung.

\section{Conclusion}

The method of pulmonectomy with a prophylactic anastomosis functioning between the lobar artery and the like-named vein on the operated side showed considerable advantages. The mean pressure in our experiments after this kind of pulmonectomy was within the limits approximating to the initial level $(355 \pm 10 \mathrm{~mm}$ $\mathrm{H}_{2} \mathrm{O}$ ) during the entire follow-up period, whereas control cross-clamping of the shunt in these animals to simulate pulmonectomy without arteriovenous anastomosis was accompanied with the rise of blood pressure in the pulmonary artery by $62 \%$.

Pulmonectomy with such functioning arteriovenous shunt on the operated side provides the possibility to avoid acute edema of the remained lung during the operation and soon after it.

Later, this shunt creates favorable hemodynamic conditions for functioning of a vascular network of the pulmonary circulation, lung tissue, and the right sections of the heart and, preventing the emergence of pulmonary arterial hypotension, eliminates one of the main causes of cor pulmonale development.

Study funding. The work was carried out within the frame of students' research work.

Conflicts of interest. The authors have no conflicts of interest to declare.

\section{References}

1. Almabaeva A.Y., Musaev A.T., Serikpaev Z.Z., Lesbekova R.B., Nurmukhanbetova D.K., Makhatov B.M., Uglanov Z.S., Zholdybaev S.S., Ismaylov D.I., Bukharbekov B.B., Aldabergenov E.N., Kolbekova A.A., Ermakhanova A.B. Description of hemodynamic changes in catamnesis after pneumonectomy. Sovremennye problemy nauki i obrazovania 2016; 1: 35.

2. Daminov R.U. The state of internal organ circulation in the postoperative period after experimental left pulmonectomy. Molodoy uchenyy 2017; 18: 117-119.

3. Voytsekhovskiy V.V., Landyshev Yu.S., Grigorenko A.A. Morphofunctional state of the bronchial system in patients with multiple myeloma. Pul'monologia 2010; 4: 49-53.

4. Lahera V., Goicoechea M., de Vinuesa S.G., Oubiña P., 
Cachofeiro V., Gómez-Campderá F., Amann R., Luño J. Oxidative stress in uremia: the role of anemia correction. J Am Soc Nephrol 2006; 17(12 Suppl 3): S174-S177, https://doi. org/10.1681/asn.2006080911.

5. Belevitin A.B., Tarasov V.A., Naumov A.V., Povarenkov A.S., Biryukov A.V., Romanovsky D Yu., Larin I.A., Kruchinenko A.Yu., Khubulava G.G. Operative isolated chemohyperthermal perfusion of the lung with ablation of pulmonary metastases. Vestnik hirurgii imeni I.I. Grekova 2010; 169(4): 12-16.

6. lakovlev A.lu., Gordeeva O.S., Denisenko A.N., Vorontsov A.lu., Ulitin D.N. Postoperative correction of the methabolism of the single lung after pulmonectomy. Khirurgiya. Zhurnal imeni N.I. Pirogova 2011; 4: 47-50.

7. Moroz V.V. Strategiya i taktika primeneniya antigipoksantov pri kriticheskikh sostoyaniyakh. V kn.: Fundamental'nye problemy reanimatologii (izbrannye lektsii $i$ obzory). Trudy Instituta obshchey reanimatologii RAMN. T. IV [Strategy and tactics of using antihypoxic agents in critical conditions. In: Fundamental problems of emergency medicine (selective lectures and reviews). Proceedings of Research Institute of General Reanimatology of RAMS. Vol. IV]. Moscow; 2005; p. 210-220.

8. Sabirov Sh.Yu., Nematov O.N., Mayusupov Sh.E., Riskiev A.A., Rakhmanov Sh.A., Nasritdinov B.I., Ermakov E.F.,
Abdumadzhitov A.M. New approaches to the vast lung resections and pulmonectomy in disseminated and drugresistant tuberculosis. Molodoy uchenyy 2017; 5.2: 49-51.

9. Shatokhin K.S., Kniazev S.P., Ermolaev V.I., Goncharenko G.M., Deeva V.S., Zaporozhets V.I., Orlova K.S., Nikitin S.V. Biodiversity of ICG mini-pigs as laboratory bioresources. Vestnik NGAU (Novosibirskii gosudarstvennyi agrarnyi universitet) 2016; 4(41): 67-74.

10. Vachnadze D.I., Breshenkov D.G., Dydykin S.S. Anesthesia in swines as a model in biomedical and biotechnological studies. Voprosy rekonstruktivnoy $i$ plasticheskoy khirurgii 2016; 4(59): 37-56.

11. Govorin A.V. Nekoronarogennye porazheniya miokarda [Non-coronarogenic myocardial injury]. Novosibirsk: Nauka; 2014.

12. Sokolova N.A., Chartorizhskaya N.N., Govorin A.V. Clinical and pathologic features of cardiac complications in patients with acute poisoning acetic acid. Serdtse: zhurnal dlya praktikuyushchikh vrachey 2011; 4(60): 245-246.

13. Almabayeva A.Y., Begalin T.B., Nazhimov B.S. Method of withdrawing animals from the experiment. Patent 11756 RK. 2002.

14. Korzhevsky D.E., Gilyarov A.B. Osnovy gistologicheskoy tekhniki [Fundamentals of histological technique]. Saint Petersburg: SpetsLit; 2010. 